\title{
Weighing in Ocular Perfusion Pressure in Managing Glaucoma
}

\author{
Fotis Topouzis* and Panayiota Founti
}

\author{
A' Department of Ophthalmology, School of Medicine, Aristotle University of Thessaloniki, AHEPA Hospital, \\ Thessaloniki, Greece
}

\begin{abstract}
The role of vascular risk factors in glaucoma is increasingly being supported by the literature, with the association between low ocular perfusion pressure (PP) and glaucoma being the most consistent result. However, we need to be cautious when interpreting these results and consider all possible confounders in the observed associations. While we assess PP through its principal components, the weight of intraocular pressure (IOP) and blood pressure (BP) in the PP equation remains unknown. Also, the role of PP in glaucoma needs to be elucidated with regards to IOP and BP fluctuation during the 24hour period and the effect of IOP-lowering and BP-lowering treatment. The complexity of the interaction of PP with other potential risk factors for glaucoma means that PP cannot be currently considered in the assessment of an individual patient. The role of PP in glaucoma warrants further research and randomized clinical trials assessing PP should include vision and/or structure preservation as end-points and ideally address all of the above issues.
\end{abstract}

\section{INTRODUCTION}

Intraocular pressure (IOP) reduction is currently the only treatment available for decreasing the risk of glaucoma progression [1]. However, glaucoma may continue to progress despite IOP reduction to targeted levels [2-4]. This indicates that factors other than IOP may play an important role in the pathogenesis of glaucoma. The role of vascular risk factors in glaucoma, particularly ocular perfusion pressure (PP), is being increasingly supported by the literature. PP is defined as the difference between arterial and venous pressure, which, in the eye, by convention equals IOP. Therefore, blood pressure (BP) and IOP are the principal components of ocular PP (PP=BP-IOP), which determines the nutritive delivery of arterial blood to capillary beds. Ocular hemodynamics in young healthy individuals, are autoregulated to maintain constant blood supply to ocular tissues, despite changes in PP [5]. However in glaucoma, there is the hypothesis of a defective autoregulation, resulting in ischemic damage and reperfusion injury [6]. In a case-control study by Gherghel et al, lower ocular PP was associated with hemodynamic alterations in progressive glaucoma patients [7]. Interestingly, this association was not found in nonprogressive glaucoma patients or healthy individuals.

\section{FROM PP TO ITS PRINCIPAL COMPONENTS: BP AND IOP}

In several population-based studies BP and IOP have been reported to be positively associated in both healthy individuals [8-11] and open-angle glaucoma (OAG) subjects [12-17]. In some studies this association was found for systolic BP, but not for diastolic BP [10, 11]. Also, most studies report a positive association between age and IOP [8, $9,12,13,18,19]$, while a negative association has been

*Address correspondence to this author at the A' Department of Ophthalmology, School of Medicine, Aristotle University of Thessaloniki, AHEPA Hospital, S. Kiriakidi 1, 54636 Thessaloniki, Greece; Tel: +302310994920; Fax: +302310839497; E-mail: ftopouzis@otenet.gr reported by few Japanese studies $[11,20]$. In addition, a positive association has been reported between age and BP $[21,22]$. Based on the above, one may suggest that age is a confounder in the BP-IOP relationship. However, in most studies the association of BP and IOP remained statistically significant after adjustment for age [8, 9, 12-17]. Therefore, it seems that the association of BP with IOP is independent of age. Although evidence may suggest an association between BP and IOP, the magnitude of IOP change associated with BP change is small, on the rate of 0.2 $0.4 \mathrm{mmHg} / 10 \mathrm{mmHg}[23]$.

Because increased IOP and glaucoma are associated, it may be expected that increased BP and glaucoma are also associated, through the BP-IOP relationship. However, hypertension has not been consistently reported as a risk factor for glaucoma [12, 13, 24-28]. An association between hypertension and glaucoma has been initially reported by non population-based studies $[24,25]$. Later, some population-based studies confirmed this association $[12,13$, 26], while others did not [27, 28]. Among studies confirming this association, results were adjusted for IOP in the Rotterdam Study [13] and the Blue Mountains Eye Study [26], while in the Egna-Neumarkt Study they were not [12].

Although, there is enough evidence on the IOP-glaucoma relationship and the BP-IOP relationship, the BP-IOPglaucoma interrelationship is more complex and remains unclear. In addition, one should consider the role of age in the above interrelationship. In the Baltimore Eye Survey, the association of BP and OAG depended on age [28]. Specifically, young hypertensives were less likely to have OAG compared to non-hypertensives, while older hypertensives were more likely to have OAG compared to non-hypertensives [28]. It is possible that age is a surrogate for duration of hypertension and that autoregulative mechanisms may be compromised after years of exposure to hypertension, and thus may predispose to OAG [29]. 


\section{THE ROLE OF PP IN GLAUCOMA - A RISK FACTOR FOR GLAUCOMA PREVALENCE, INCIDENCE AND PROGRESSION}

Low diastolic PP has been consistently associated with increased glaucoma prevalence in population-based studies. In the Baltimore Eye Survey [28], the Barbados Eye Study [27] and the Rotterdam Study [30] low diastolic PP was a risk factor for glaucoma prevalence. Having findings to the same direction, the Egna-Neumarkt Study [12] and the Proyecto VER [31] found that glaucoma prevalence decreases progressively with increased diastolic PP.

Further to that, low diastolic PP has been associated with increased glaucoma incidence. In the Barbados Eye study, a population-based cohort study of 3222 African origin participants with a follow-up of over 9 years, OAG incidence was 4.4\% [32]. Among baseline factors included in the analysis, all lower PPs, meaning systolic, diastolic and mean $\mathrm{PP}$, were associated with an increased risk of $\mathrm{OAG}$ incidence. In addition, the Early Manifest Glaucoma Trial (EMGT), a prospective randomized clinical trial (RCT) of 255 Caucasian participants with a median follow-up of 8 years, evaluated risk factors for progression of manifest OAG [33]. Overall progression was 67\%, while baseline systolic $\mathrm{PP} \leq 125 \mathrm{~mm} \mathrm{Hg}$ was a risk factor for $\mathrm{OAG}$ progression (OR, 1.42; 95\% CI, 1.04-1.94).

Although findings from cross-sectional studies and the EMGT are consistent on low PP as risk factor for glaucoma, we need to be cautious when interpreting these results. In all cross-sectional studies reporting low PP as a risk factor for glaucoma prevalence results were not adjusted for IOPlowering and BP-lowering treatment. In addition, even though results were adjusted for IOP, IOP-lowering and BPlowering treatment in the incidence report of the Barbados Eye Study and the EMGT, residual confounding may still exist.

\section{PP: A TRICKY VARIABLE WITH REGARDS TO IOP AND BP}

PP can be affected by both its components, meaning IOP and BP. However, among the two "players" we do not know who is really playing the game. It could be only IOP, only BP or a combination of both. Even if we assume the third case which seems more reasonable, we do not know the weight of each variable to PP and whether it is the same for the whole IOP spectrum. For example, the Egna-Neumarkt Study did not find an association between low diastolic PP and increased glaucoma prevalence in normal-tension glaucoma [12]. According to the authors, this may be related to the limited number of cases in the normal-tension glaucoma group. However, this might also be because of different pathogenic mechanisms in normal-tension compared to high-tension glaucoma or simply because PP cannot be very low in normal-tension glaucoma due to low IOP values. This hypothesis may also be supported by the Rotterdam Study results, where $\mathrm{PP}<50 \mathrm{mmHg}$ was positively associated with high-tension glaucoma, while it was inversely associated with normal-tension glaucoma (OR, 0.25 ; 95\% CI, 0.10-0.63) [30].

Further to that, there are few reports on how IOP and BP fluctuate at different time-points during the 24hour period
$[34,35]$ and therefore we do not know the result of IOP and BP fluctuation on PP. In a recent report by Kida T et al. PP fluctuation was estimated based on both IOP and BP measurements during the 24-hour period [35]. However, this study involved only healthy eyes, while all measurements were performed in the sitting position. More studies will be needed to determine the effect of IOP and BP fluctuation on $\mathrm{PP}$ in glaucoma subjects and in real-life conditions.

In addition, evidence suggests that PP can be influenced by high IOP alone or by IOP-lowering treatment. In the Barbados Eye Study and the EMGT, results were adjusted for IOP, IOP-lowering and BP-lowering treatment [32, 33]. However, one may not exclude residual confounding. It is possible that there is a different significance of $\mathrm{BP}$ depending on the IOP. In the EMGT subgroup analyses with regards to IOP, systolic $\mathrm{BP} \leq 160 \mathrm{mmHg}$ was associated with progression in patients with baseline IOP $<21 \mathrm{mmHg}$ [33]. However, only systolic PP $\leq 125 \mathrm{mmHg}$, but not systolic BP $\leq 160 \mathrm{~mm} \mathrm{Hg}$ was associated with progression in patients with higher baseline IOP. This suggests that the association was possibly driven by high IOP, leading to lower systolic PP.

Another issue that should be considered in order to determine the role of PP in glaucoma is the effect of BPlowering treatment. The same level of BP may have a different significance in those treated for hypertension compared to non-hypertensive subjects. In a Thessaloniki Eye Study report involving 232 non-glaucoma subjects examined with the Heidelberg Retina Tomograph, low diastolic PP, low diastolic BP and the use of BP-lowering treatment were significantly associated with increased cupping and decreased rim area only in subjects with decreased diastolic BP $(<90 \mathrm{~mm} \mathrm{Hg})$ as a result of antihypertensive treatment [36]. Similarly, in the Rotterdam Study low diastolic PP was associated with increased glaucoma prevalence only in subjects treated for hypertension [30]. The type and duration of BP-lowering treatment may also contribute to glaucoma risk. In the European Glaucoma Prevention Study the use of diuretics was an independent risk factor for OAG incidence (OR, 2.41; 95\% CI, 1.12-5.19) [37]. This suggests that the type of BP-lowering treatment may be an additional variable to consider when assessing PP.

\section{CONCLUSION}

Evidence from the literature may support an ageindependent positive association between BP and IOP. However, there is still controversy on the role of hypertension in glaucoma, while the interrelationship between BP, IOP and glaucoma remains unclear. Understanding PP and its role in glaucoma could provide some insight into how these variables interfere and ultimately increase our knowledge on glaucoma pathogenesis. However, there are several factors which should be considered when interpreting the observed associations related to PP. The apparent complexity of the interaction of PP with other potential risk factors for glaucoma suggests that PP warrants further research and cannot be currently considered in the assessment of an individual patient. 
In order to be able to introduce PP in clinical practice, we should first determine and quantify the role of PP in glaucoma risk. This would mostly require RCTs specifically designed to address PP. Such RCTs should include vision and/or structure preservation as end-points and involve longterm follow-up.

\section{REFERENCES}

[1] Lichter PR, Musch DC, Gillespie BW, et al. CIGTS study group. Interim clinical outcomes in the collaborative initial glaucoma treatment study comparing initial treatment randomized to medications or surgery. Ophthalmology 2001; 108: 1943-53.

[2] Kass MA, Heuer DK, Higginbotham EJ, et al. The ocular hypertension treatment study: a randomized trial determines that topical ocular hypotensive medication delays or prevents the onset of primary open-angle glaucoma. Arch Ophthalmol 2002; 120: 701-13.

[3] Heijl A, Leske MC, Bengtsson B, Hyman L, Bengtsson B, Hussein M. Early manifest glaucoma trial group. reduction of intraocular pressure and glaucoma progression: results from the early manifest glaucoma trial. Arch Ophthalmol 2002; 120: 1268-79.

[4] Comparison of glaucomatous progression between untreated patients with normal-tension glaucoma and patients with therapeutically reduced intraocular pressures. Collaborative Normal-Tension Glaucoma Study Group. Am J Ophthalmol 1998; 126: 487-97.

[5] Harris A, Werne A, Cantor LB. Vascular abnormalities in glaucoma: from population-based studies to the clinic? Am J Ophthalmol 2008; 145: 595-7.

[6] Choi J, Kim KH, Jeong J, Cho HS, Lee CH, Kook MS. Circadian fluctuation of mean ocular perfusion pressure is a consistent risk factor for normal-tension glaucoma. Invest Ophthalmol Vis Sci 2007; 48: 104-11.

[7] Gherghel D, Orgül S, Gugleta K, Gekkieva M, Flammer J. Relationship between ocular perfusion pressure and retrobulbar blood flow in patients with glaucoma with progressive damage. Am J Ophthalmol 2000; 130: 597-605.

[8] Wu SY, Leske MC. Associations with intraocular pressure in the Barbados Eye Study. Arch Ophthalmol 1997; 115: 1572-6.

[9] Hennis A, Wu SY, Nemesure B, Leske MC, Barbados eye studies group. Hypertension, diabetes, and longitudinal changes in intraocular pressure. Ophthalmology 2003; 110: 908-14.

[10] McLeod SD, West SK, Quigley HA, Fozard JL. A longitudinal study of the relationship between intraocular and blood pressures. Invest Ophthalmol Vis Sci 1990; 31: 2361-6.

[11] Nomura H, Shimokata H, Ando F, Miyake Y, Kuzuya F. Agerelated changes in intraocular pressure in a large Japanese population: a cross-sectional and longitudinal study. Ophthalmology 1999; 106: 2016-22.

[12] Bonomi L, Marchini G, Marraffa M, et al. Vascular risk factors for primary open angle glaucoma: the Egna-Neumarkt Study. Ophthalmology 2000; 107: 1287-93.

[13] Dielemans I, Vingerling JR, Algra D, Hofman A, Grobbee DE, de Jong PT. Primary open-angle glaucoma, intraocular pressure, and systemic blood pressure in the general elderly population. The rotterdam study. Ophthalmology 1995; 102: 54-60.

[14] Mitchell P, Lee AJ, Wang JJ, Rochtchina E. Intraocular pressure over the clinical range of blood pressure: blue mountains eye study findings. Am J Ophthalmol 2005; 140: 131-2.

[15] Klein BE, Klein R, Knudtson MD. Intraocular pressure and systemic blood pressure: longitudinal perspective: the beaver dam eye study. Br J Ophthalmol 2005; 89: 284-7.

[16] Nemesure B, Wu SY, Hennis A, Leske MC, Barbados eye studies group. Factors related to the 4-year risk of high intraocular pressure: the Barbados eye studies. Arch Ophthalmol 2003; 121: 856-62.

[17] Wu SY, Nemesure B, Hennis A, Leske MC, Barbados eye studies group. Nine-year changes in intraocular pressure: the Barbados eye studies. Arch Ophthalmol 2006; 124: 1631-6.

[18] Klein BE, Klein R. Intraocular pressure and cardiovascular risk variables. Arch Ophthalmol 1981; 99: 837-9.

[19] Klein BE, Klein R, Linton KL. Intraocular pressure in an American community. The beaver dam eye study. Invest Ophthalmol Vis Sci 1992; 33: 2224-8.

[20] Shiose Y, Kawase Y. A new approach to stratified normal intraocular pressure in a general population. Am J Ophthalmol 1986; 101: 714-21.

[21] Burt VL, Whelton P, Roccella EJ, et al. Prevalence of hypertension in the US adult population. Results from the third national health and nutrition examination survey, 1988-1991. Hypertension 1995; 23: 305-13.

[22] Franklin SS, Gustin W 4th, Wong ND, et al. Hemodynamic patterns of age-related changes in blood pressure. The framingham heart study. Circulation 1997; 96: 308-15.

[23] Deokule S, Weinreb RN. Relationships among systemic blood pressure, intraocular pressure, and open-angle glaucoma. Can J Ophthalmol 2008; 43: 302-7.

[24] Katz J, Sommer A. Risk factors for primary open angle glaucoma. Am J Prev Med 1988; 4: 110-4.

[25] Wilson MR, Hertzmark E, Walker AM, Childs-Shaw K, Epstein DL. A case-control study of risk factors in open angle glaucoma. Arch Ophthalmol 1987; 105: 1066-71.

[26] Mitchell P, Lee AJ, Rochtchina E, Wang JJ. Open-angle glaucoma and systemic hypertension: the blue mountains eye study. J Glaucoma 2004; $13: 319-26$.

[27] Leske MC, Connell AM, Wu SY, Hyman LG, Schachat A. Risk factors for open-angle glaucoma. The Barbados eye study. Arch Ophthalmol 1995; 113: 918-24.

[28] Tielsch JM, Katz J, Sommer A, Quigley HA, Javitt JC. Hypertension, perfusion pressure, and primary open-angle glaucoma. A population-based assessment. Arch Ophthalmol 1995; 113: 216-21.

[29] Boland MV, Quigley HA. Risk factors and open-angle glaucoma: classification and application. J Glaucoma 2007; 16: 406-18.

[30] Hulsman CA, Vingerling JR, Hofman A, Witteman JC, de Jong PT. Blood pressure, arterial stiffness, and open-angle glaucoma: the rotterdam study. Arch Ophthalmol 2007; 125: 805-12.

[31] Quigley HA, West SK, Rodriguez J, Munoz B, Klein R, Snyder R. The prevalence of glaucoma in a population-based study of hispanic subjects: proyecto VER. Arch Ophthalmol 2001; 119: 1819-26.

[32] Leske MC, Wu SY, Hennis A, Honkanen R, Nemesure B. BESs study group. risk factors for incident open-angle glaucoma: the barbados eye studies. Ophthalmology 2008; 115: 85-93.

[33] Leske MC, Heijl A, Hyman L, Bengtsson B, Dong L, Yang Z, EMGT group. Predictors of long-term progression in the early manifest glaucoma trial. Ophthalmology 2007; 114: 1965-72.

[34] Liu JH, Sit AJ, Weinreb RN. Variation of 24-hour intraocular pressure in healthy individuals: right eye versus left eye. Ophthalmology 2005; 112: 1670-5.

[35] Kida T, Liu JH, Weinreb RN. Effect of aging on nocturnal blood flow in the optic nerve head and macula in healthy human eyes. J Glaucoma 2008; 17: 366-71.

[36] Topouzis F, Coleman AL, Harris A, et al. Association of blood pressure status with the optic disk structure in non-glaucoma subjects: the thessaloniki eye study. Am J Ophthalmol 2006; 142: 60-7.

[37] Miglior S, Torri V, Zeyen T, Pfeiffer N, Vaz JC, Adamsons I, EGPS Group. Intercurrent factors associated with the development of open-angle glaucoma in the European glaucoma prevention study. Am J Ophthalmol 2007; 144: 266-75. 